\title{
The effect of pipe collectors in reducing the drainage coefficient rate
}

\begin{abstract}
A high groundwater table and soil salinity, especially in arid regions, often cause serious problems for agriculture. In irrigated areas the subsurface drainage can be an effective technique to lower the depth of the groundwater table and reduce soil salinity. In drainage systems, lateral pipes are designed to collect the free water from soil and convey it into collectors. In other words, collectors are commonly designed to convey drainage water from laterals downstream, while the laterals play an additional role in removing excess water from irrigated land. The present research was conducted to investigate the effects of collectors in discharging excess water from soil using a laboratory-tank model. The results indicated that on average $24 \%$ of drainage water was directly discharged through the collector pipe when the hydraulic gradient of the flow was sloped toward the collector pipe. Hence, it was concluded that, with proper monitoring, collectors were capable of reducing the drainage coefficient from an average of 32.5 to $24.5 \mathrm{~mm} /$ day, while drain spacing of the laterals can increase the results by about $15 \%$ in comparison with the present situation.
\end{abstract}

